\title{
Bionony arnd Beharior \\ Occurrence and ecological data on an exotic solitary bee accidentally introduced in Brazil
}

\author{
Charles Fernando dos Santos ${ }^{\bowtie}\left({ }^{\circ}\right.$, Cristiane Andrade de Barros ${ }^{\oplus}$, Rosana Halinski® \& Betina Blochtein
}

Pontifícia Universidade Católica do Rio Grande do Sul, Brazil

EntomoBrasilis 13: e891 (2020)

Edited by:

Wesley Dáttilo

Article History:

Received: 10.i.2020

Accepted: 18. viii.2020

Published: 21.ix.2020

\section{Corresponding author:}

Charles Fernando dos Santos

乃 charles.santos@pucrs.br

Funding agencies:

¿ Coordenação de Aperfeiçoamento de Pessoal de Nível Superior; Conselho Nacional de Desenvolvimento Científico e Tecnológico

\begin{abstract}
Currently, there is a global concern regarding exotic species due to, among other factors, their great ability to reproduce and spread rapidly through the novel environment. As such, these species often compete for nesting places and food resources or convey pathogens. Anthidium manicatum (Linnaeus) (Hymenoptera: Megachilidae) is a non-native solitary bee occurring in Brazil. This study aimed to collect data about the occurrence sites of this species to investigate the historical sequence of its spread throughout the country. Based on this, we estimated population data such as the number of males and females, phenology and bioclimatic niche overlap with native species. The occurrence records were retrieved from speciesLink and Global Biodiversity Information Facility. All analyses were performed in R. The collected data demonstrate that, except for the 1960s, the records of the occurrence of $A$. manicatum in Brazil are few and constant, being notified since the mid-1930s in at least nine Brazilian states. In total, 778 individuals were sampled, with males being recorded about 1.7 times more than females. This species seems to be bivoltine, with generations in May and November. Anthidium manicatum showed a low and moderate bioclimatic niche overlap with two native species, Anthidium sertanicola Moure \& Urban and Anthidium latum Schrottky, respectively. These data provide relevant information on the biology and status of $A$. manicatum in Brazil. However, since most Brazilian scientific collections have not digitalized their data in the platforms consulted here, some ecological features described here may be underestimated.
\end{abstract}

Keywords. Anthidium manicatum; Dispersal; Exotic species, Megachilidae; Solitary Bee
D) ees belong to the order Hymenoptera and are grouped into a clade named Anthophila ("flower lovers") (GRIMALD \& ENGEL 2005). The diversity and conservation of these insects are of global importance for the maintenance of wild plants and agriculture due to the cross-pollination they perform (KLeIn et al. 2007; Ollerton et al. 2011). Despite this importance, bee populations are declining worldwide, which may directly affect the aforementioned benefits (PotTs et al., 2010). Among the factors contributing to bee reduction, we may highlight the introduction or invasion of species (PotTs et al. 2010; Morales et al. 2013; Acosta et al. 2016).

The introduction (intended action) or invasion (non-intended action) of bee species to places where they historically do not occur may bring serious ecological effects to the local fauna (Russo 2016; Vollet-Neto et al. 2018). Overall, such organisms are $r$-strategists, i.e., they show a high fecundity rate and an elevated dispersal capacity (SAKAl et al. 2001). As a result, their effects on the environment may be disastrous since they (i) compete for nest substrates, (ii) compete for food resources, (iii) transmit pathogens, (iv) alter plantinsect interaction, among others (Russo 2016; Vollet-Neto et al. 2018). In an attempt to avoid such issues, most countries are regulating the management and transport of bees within their territories to diminish the chances of introductions or accidental invasions of novel (exotic) species (IPBES 2016).

Brazil is a large nation with an area of $8,516,000 \mathrm{~km}^{2}$ Thus, monitoring exotic bee species becomes an arduous task. Almost 65 years ago (1956), the state of São Paulo (municipality of Rio Claro) was an epicenter of the most famous bee introduction (Apidae: Apini: Apis mellifera scutellata Lepeletier), the African honey bee, in the world (Michener 1973). In a few decades, this exotic social bee was well-established, spread and hybridized (Africanized honey bees) in Brazil and other Latin American countries (MicHeNER 1973). Due to this well-known case, there is currently a new concern with the commercial importation of bumblebees (Apidae: Bombini: Bombus terrestris Linnaeus) from Europe to South America. This exotic bumblebee is negatively affecting native species of the same genus in Chile and Argentina (Morales et al. 2013; Aizen et al. 2019). A recent study has suggested that $B$. terrestris has a high potential to invade Brazil in the oncoming years (Acosta et al. 2016).

In the mid-1930s, a non-native solitary bee species [Megachilidae: Anthidiini: Anthidium manicatum (Linnaeus, 1758)], Figure 1, was detected in Brazil. Anthidium manicatum is native to Europe, Western Asia and Northern Africa (Palearctic region) (Strange et al. 2011). However, it has invaded several countries such as the United States, Latin American nations and New Zealand (Strange et al. 2011; Gonzalez \& Griswold 2013). Data suggest that, in Brazil, A. manicatum was accidentally introduced via the importation of wooden furniture from Europe which likely harbored nests of this species (Moure \& Urban 1964, apud Silveira et al. 2002).

While A. manicatum is an exotic species of Anthidium in Brazil, there are five natives species of this genus in the country: Anthidium isabelae Urban, Anthidium larocai Urban, Anthidium latum Schrottky, Anthidium sanguinicaudum Schwarz and Anthidium sertanicola Moure \& Urban (SILVEIRA et al. 2002; URBAN 2002). Bees of this genus are known as wool carder bees because they scrape hairs from leaves and twigs of 

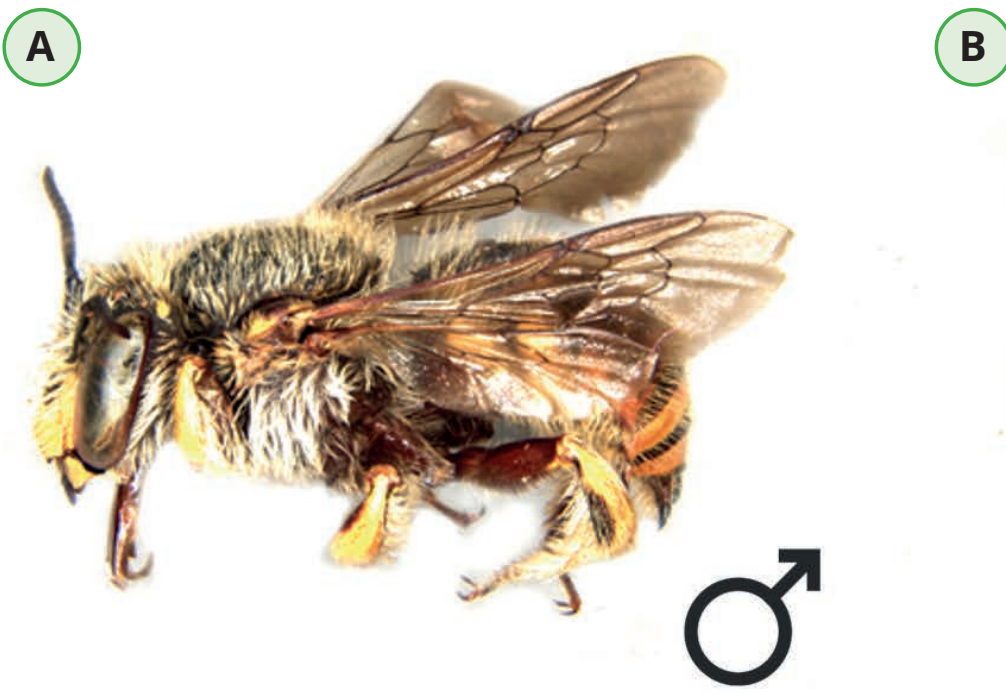

Figure 1. Male of Anthidium manicatum (Hymenoptera: Megachilidae). A - Lateral view, B - Dorsal view.

plants of the family Lamiaceae and use them to build their nests (Strange et al. 2011; Gonzalez \& Griswold 2013).

Males and females of $A$. manicatum are conspicuous due to both their large size ( $\delta$ : 12.3-17.7 mm; of: 9.2-12.2 mm) and their yellow-banded black abdomens (StRANGe et al. 2011). Anthidium manicatum males are as active as females (WIRTZ et al. 1992). Yet, A. manicatum females have a prolonged sexual receptivity and nest on pre-existing cavities of the aforementioned substrates, in which they store food (pollen and nectar) and, immediately after, lay their eggs (WIRTz et al. 1992; StRAnge et al. 2011).

Anthidium manicatum males defend plants that are attractive to females against conspecific males and mate with females as soon as they enter their territories (WIRTz et al. 1992; MUELLER \& Wolf-Mueller 1993). Males defend their territories using thorny projections of the distal region of their abdomens against the wings of competitors (StRANGe et al. 2011; GonZAlez \& GRISWOLD 2013). This behavior facilitates the detection of males in environments they inhabit (StRANGe et al. 2011; GonZALEZ \& GRISWOLD 2013).

Although interesting, A. manicatum is an exotic species in Brazil. Thus, by considering the ecological threats that a nonnative bee species may represent to local populations, the main goal of this study was to conduct a chronological survey of the occurrence of $A$. manicatum to investigate its current status in Brazil. Therefore, we evaluated (i) the total number of occurrences in data available in digital platforms; (ii) the male-female ratio; (iii) the Brazilian states where $A$. manicatum has been recorded according to the consulted database; (iv) the number of sampled individuals over the decades; (v) the species phenology (i.e., annual activity pattern) using a circular analysis; and (vi) potential bioclimatic niche overlap between A. manicatum and two native species of Anthidium with enough data to carry out such an analysis. We believe that the results herein provided will help future research and drive field works particularly devoted to monitoring this exotic solitary bee species in Brazil.

\section{MATERIAL AND METHODS}

Occurrence data. We surveyed the occurrence of $A$. manicatum in Brazil in two digital databases: speciesLink (http://splink.cria.org.br/) and Global Biodiversity Information Facility (GBIF - https://www.gbif.org/). Data of the latter were retrieved from GIBF using the function 'occ_search' (country='BR') of the package rgibf (CHAMBERLAIN et al. 2020) for R (IhAKa \& GentLeman 1996; R Core Team 2018). In both databases, we searched for the following data: geographic coordinates, names of collections and museums where specimens were deposited, recorded date, number of sampled individuals and whether they were male or female.

Data analysis. Circular analysis: The activity period of $A$. manicatum in Brazil was evaluated with a circular analysis using the function 'circular' from the package circular (AgOSTINELLI \& LUND 2017). Our temporal data were the sampling months, whereas the angles were our reference measure and the hours were our measure units. The directionality was tested with Rao's Spacing using the function 'rao.spacing.test' of circular.

Bioclimatic niche overlap: Since $A$. manicatum is an exotic bee, it most likely inhabits a fraction of or the entire region already inhabited by native Anthidium bees. Thus, we evaluated a potential bioclimatic niche overlap (see below) between exotic ( $A$. manicatum) and native ( $A$. isabelae, $A$. larocai, $A$. latum, $A$. sanguinicaudum, and $A$. sertanicola) Anthidium bees. The occurrence data of native species were obtained using the functions 'name_backbone' and 'occ search' [country="BR"] of the package rgibf (CHAMBERLAIN et al. 2020). Since georeferenced data were not available for $A$. isabelae and $A$. larocai, and since only two occurrences were retrieved for $A$. sanguinicaudum, niche overlap was assessed between $A$. manicatum $(n=57)$ and both A. latum $(n=63)$ and $A$. sertanicola $(n=22)$. Numbers inside brackets indicate unique (non-repeated) localities, totaling 142 geographic coordinates.

Bioclimatic variables (Bio1-Bio19; https://worldclim.org/ data/bioclim.html) of each occurrence point were obtained using the function 'getData' of the package raster (HIJMANs 2017). These variables were then incorporated into the data frame of all three Anthidium species using the functions 'SpatialPoints' of the package sp (BIVAND et al. 2013), and 'extract' of the package raster. However, before proceeding with the analysis, we evaluated the collinearity between all bioclimatic variables using the function 'vifstep' of the package usdm (NAImı et al. 2014). Only non-collinear variables were used to analyze niche overlap (see results).

Finally, the bioclimatic niche overlap between the three Anthidium species was performed using the functions 'overlap' and 'overlap.plot' of the package nicheROVER (LYSY et al. 2014) after 2,000 iterations. A high overlap suggests a similar use of their bioclimatic region. This metric is referred to as Niche region $\left(N_{R}\right)$, which is defined as a probability of $95 \%$ of an individual of group $A$ to be found within the $N_{R}$ of group B (SWANSON et al. 2015). Since this measure is asymmetric, the probability of $A$. manicatum individuals to be 
found in the bioclimatic $N_{R}$ of $A$. latum and $A$. sertanicola may be different from the probability of the latter to be found in the bioclimatic $N_{R}$ of $A$. manicatum. It will depend on how these bee species use their niche areas (SWAnson et al. 2015).

\section{RESULTS}

We obtained 1,235 occurrence points of $A$. manicatum in Brazil. However, after we removed incongruent and overlapped data, the final number was 778, of which 489 were of males and 289 of females. This proportion indicates that, in digital platforms (speciesLink, GBIF), there are 1.7 more males than females. These specimens are deposited at the following institutions: (a) "Coleção Entomológica Paulo Nogueira-Neto", Instituto de Biociências, Universidade de São Paulo, (b) “Coleção Entomológica Pe. Jesus Santiago Moure (Hymenoptera)", "Departamento de Zoologia", Universidade Federal do Paraná, (c) "Coleção de Abelhas", Museu de Ciências e Tecnologia, Pontifícia Universidade Católica do Rio Grande do Sul, (d) "Coleção Entomológica”, Universidade Federal de Pernambuco, (e) "Laboratório de Ecologia e Biogeografia", Insetos da Caatinga, Universidade Federal de
Campina Grande, (f) Insect Collection, Illinois Natural History Survey, USA and (g) Snow Entomological Museum Collection, Biodiversity Institute, University of Kansas, USA. On the other hand, the occurrence data of $A$. latum and $A$. sertanicola were all retrieved from "Coleção Entomológica Pe. Jesus Santiago Moure (Hymenoptera)", “Departamento de Zoologia”, Universidade Federal do Paraná.

According to the available data, A. manicatum in Brazil has been observed in, at least, nine states: Minas Gerais (59.7\%), São Paulo (15.6\%), Santa Catarina (12\%), Paraná (6.8\%), Rio Grande do Sul (2.3\%), Bahia (1.6\%), Rio de Janeiro (1.3\%), Tocantins (0.5\%) and Ceará (0.2\%). Most available records seem to be distributed along the Brazilian coast (Figure 2). The first recorded specimen of $A$. manicatum is from 1934 with a single individual in Rio de Janeiro, and the last one is from 2020, in Paraná, again with a single individual (Figure 3); remembering that such records are based on data available on digital platforms. The year with the largest number of sampled individuals is 1963, thirty years after the first observation, with 418, most from Minas Gerais (Figure 3).

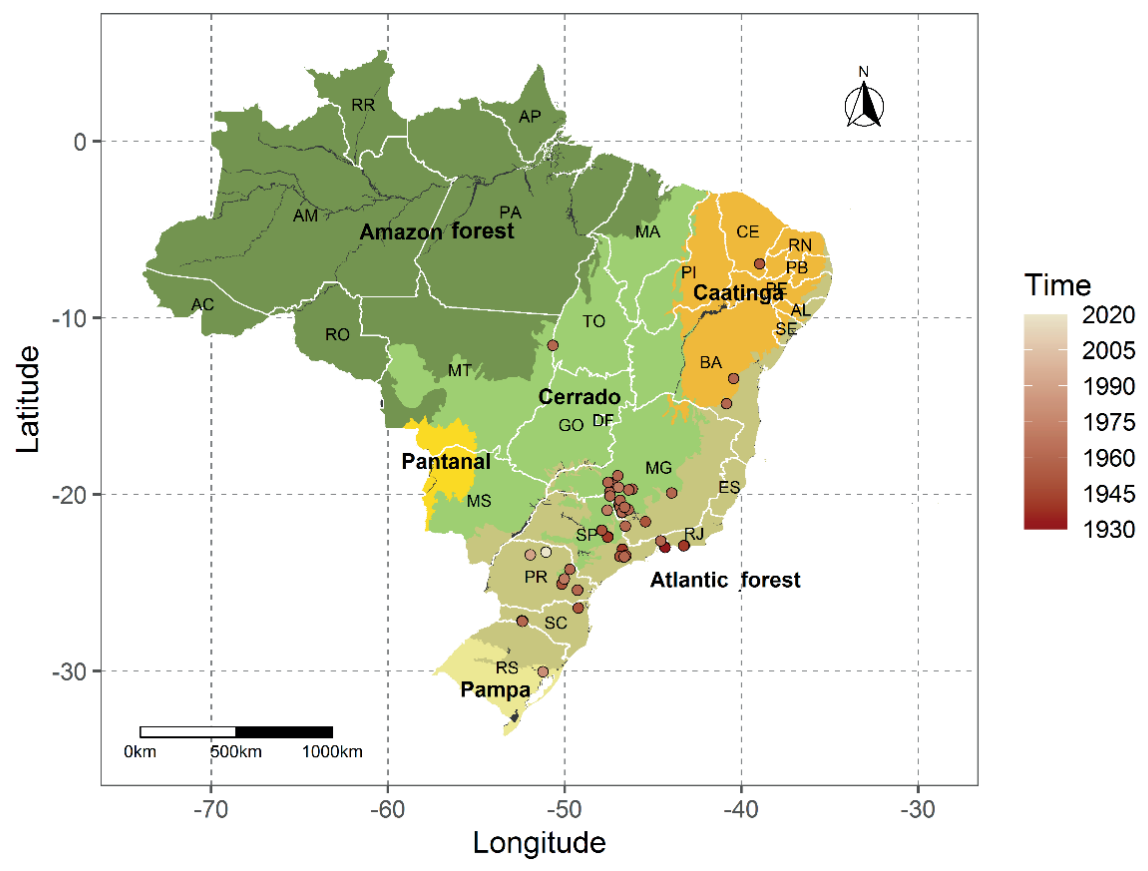

Figure 2. Occurrence data of Anthidium manicatum (Hymenoptera: Megachilidae) in Brazil according to consulted databases: speciesLink (http://splink.cria.org.br/) and GIBF (https://www.gbif.org/).

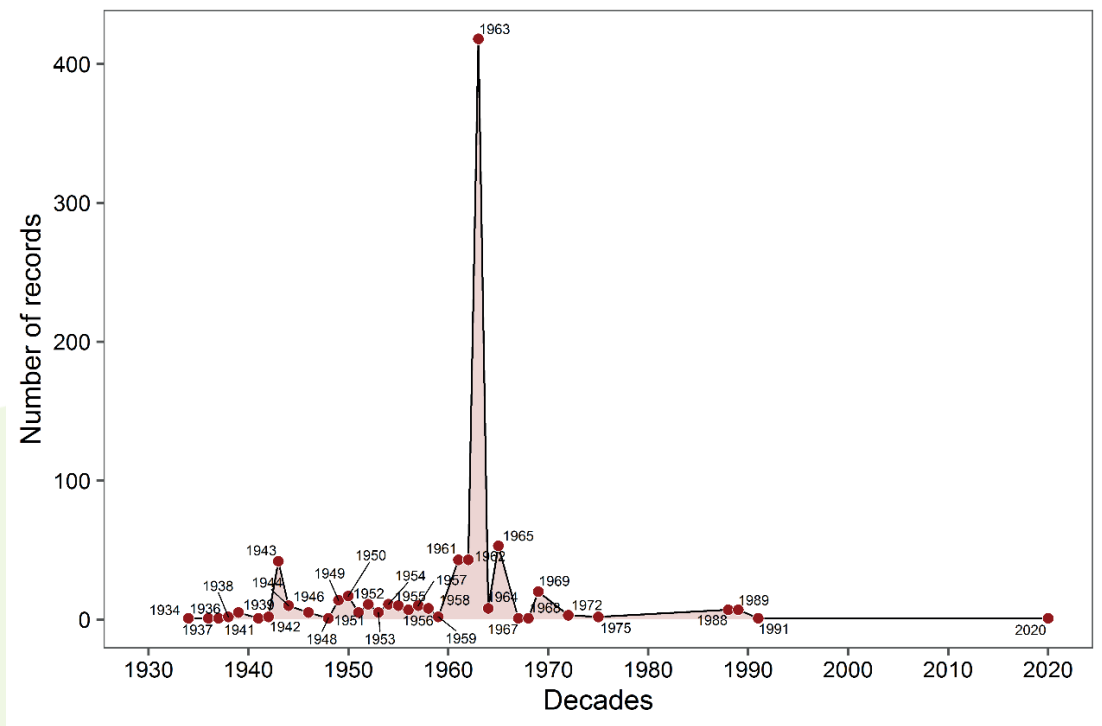

Figure 3. Number of records and temporal notification on the occurrence of Anthidium manicatum (Hymenoptera: Megachilidae) in Brazil. 
The annual activity pattern of $A$. manicatum may take place throughout the year with a clear directional tendency to be bivoltine (two generations per year) in their phenology (Rao's Spacing $=351.74, p<0.001)$ since the peaks of activity were in May (late autumn) and November (late spring) (Figure 4).

Of the 19 bioclimatic variables, nine were non-collinear (Table 1) and adequate for the next analysis. Our data show that A. manicatum may overlap, on average, 4.7\% (2 - 8: 95\% confidence interval) of the bioclimatic $\mathrm{N}_{\mathrm{R}}$ of $A$. sertanicola. Thus, there is a low probability of a randomly sampled exotic

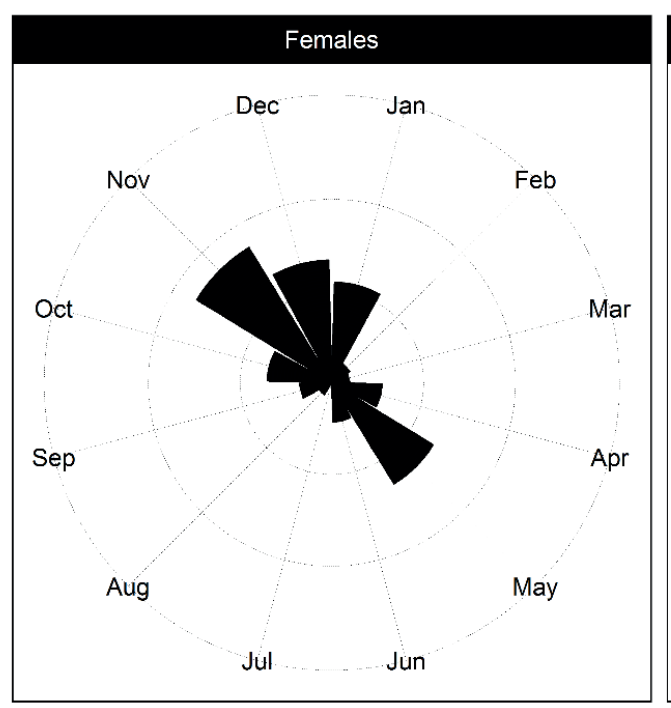

individual to be found in the bioclimatic $\mathrm{N}_{\mathrm{R}}$ of this native Anthidium species. On the other hand, the probability of $A$. manicatum to be found in the bioclimatic $\mathrm{N}_{\mathrm{R}}$ of $A$. latum is on average almost three times higher (15.2\%; $10-21$ : 95\% confidence interval), Figure 5.

\section{DISCUSSION}

Our data show that $A$. manicatum remains a little sampled species in Brazil since its first observation almost nine decades ago (1934-2020), except for 1963 when a peak of individuals was recorded. The few samplings of this species may be due

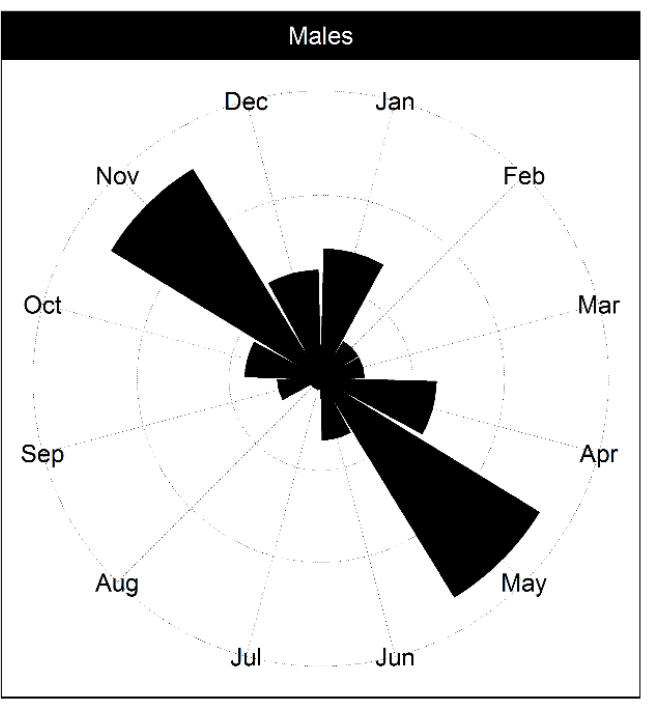

Figure 4. Circular plot. Phenology and bivoltinism of females and males of Anthidium manicatum (Hymenoptera: Megachilidae) in Brazil.

Table 1. Nine non-collinear bioclimatic variables and their means across the range of three Anthidium species (Hymenoptera: Megachilidae), two native $(*)$ and one exotic (**). Note: Mean \pm standard deviation; color indicates lower (yellow), medium (light green) and higher (dark green) values of bioclimatic variables.

\begin{tabular}{lccccccccc}
\hline \multirow{2}{*}{ Species } & \multicolumn{4}{c}{ Temperature $\left({ }^{\circ} \mathbf{C}\right)$} & \multicolumn{4}{c}{ Precipitation $(\mathbf{m m})$} \\
\cline { 2 - 10 } & BIO2 & BIO3 & BIO8 & BIO9 & BI013 & BIO14 & BIO15 & BIO18 & BIO19 \\
\hline Anthidiuam latum* & $11.1 \pm 1.5$ & $6.7 \pm 0.4$ & $24.1 \pm 1.9$ & $21.2 \pm 2.9$ & $238 \pm 58$ & $15 \pm 13$ & $74 \pm 16$ & $406 \pm 200$ & $93 \pm 61$ \\
Anthidium manicatum** & $11.0 \pm 1.1$ & $6.2 \pm 0.5$ & $21.7 \pm 2.1$ & $17.4 \pm 2.7$ & $236 \pm 53$ & $40 \pm 38$ & $57 \pm 25$ & $555 \pm 142$ & $160 \pm 122$ \\
Anthidium sertanicola* & $11.6 \pm 1.3$ & $6.4 \pm 0.5$ & $21.7 \pm 2.5$ & $17.7 \pm 2.7$ & $269 \pm 46$ & $24 \pm 28$ & $68 \pm 20$ & $631 \pm 112$ & $113 \pm 95$ \\
\hline
\end{tabular}

$\mathrm{BIO} 2$ - Mean diurnal range; BIO3 - Isothermality (oscillation of day-to-night temperatures relative to the summer-to-winter (annual) oscillations); BIO8 - Mean temperature in the wettest trimester; BIO9 - Mean temperature in the driest trimester; BIO13 - Precipitation in the wettest month; BIO14 - Precipitation in the driest month; BIO15 - Precipitation seasonality (coefficient of variation); BIO18 - Precipitation in the warmest trimester; BIO19 - Precipitation in the coldest trimester.

A

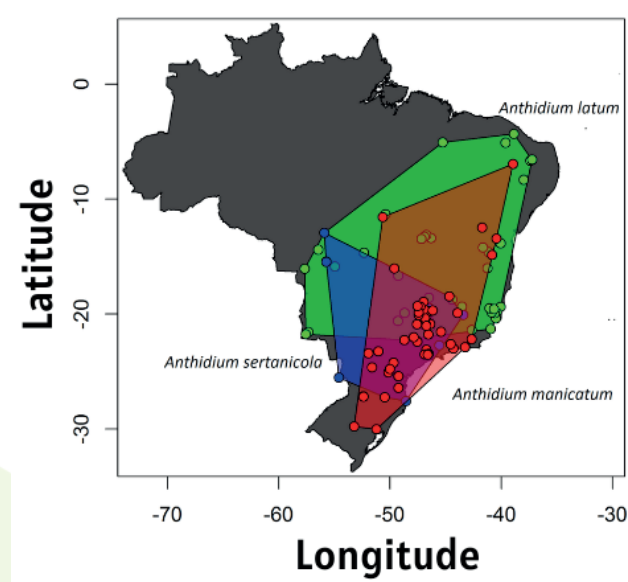

B

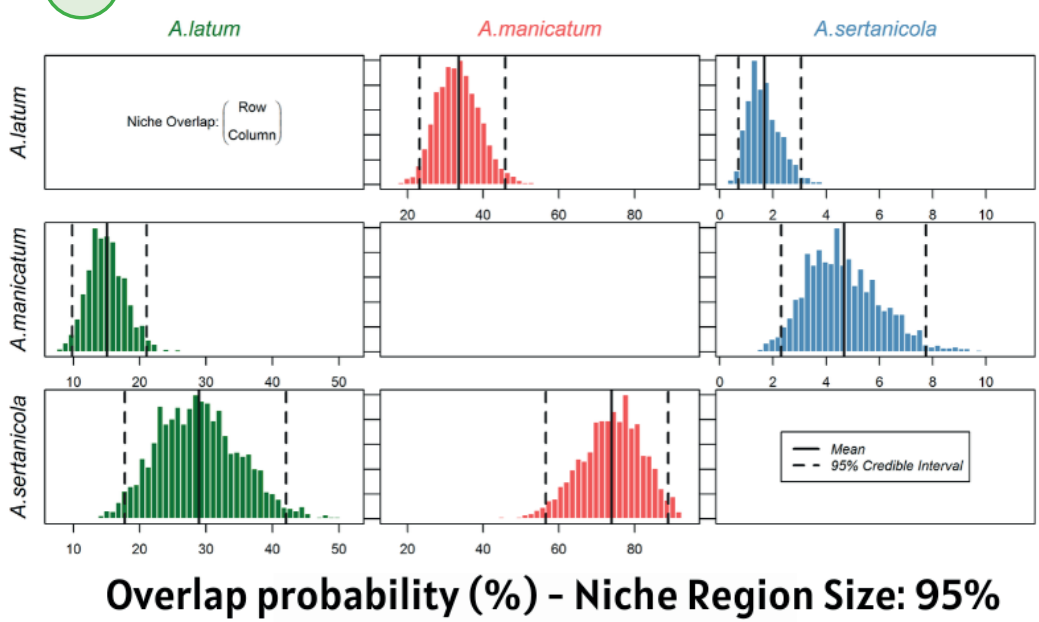

Figure 5. A - Polygons (convex hull, i.e., incorporating outer geographic coordinates) showing the distribution range of two native Anthidium bees in Brazil $(A$. latum = green; $A$. sertanicola $=$ blue) and an exotic species $(A$. manicatum $=$ red). B - Probability of bioclimatic niche region (95\%) between the three Anthidium species in panel A. This plot demonstrates both the width and the posterior probability of a random individual of the species identified in the $y$-axis (i.e. lines) to be found in the niche of the species named in the column heading. Note: in B, the black vertical line represents the average overlap and dashed black lines indicate the confidence intervals at 95\%. 
to both their solitary habits and because field collections were not particularly focused on this species. Yet, the peak of records in the 1960s may be related to an increased collection effort on that period, most likely due to funding of research for this purpose, which was not repeated in the following decades.

The amount of occurrence data of $A$. manicatum individuals ( $n$ $=778$ ) represents ca. $9.8 \%$ of global data, which reaches 7,925 occurrence points according to data extracted from GBIF in our analysis. However, these data may be underestimated for Brazil because this bee species is solitary and its long-term continuous sampling is impaired. Furthermore, Brazilian scientific collections and museums may not have yet made all occurrence data of $A$. manicatum available in the digital platforms consulted by us.

We also cannot neglect the possibility that researchers are collecting A. manicatum individuals but have not yet deposited them in collections or conducted their species determination, which delays their on-line record. This bottleneck can be depicted with the following examples: (a) in Ceará (Limoeiro do Norte), northeast Brazil, one individual was observed in 2009 (BB, personal observation); (b) in Paraná (Maringá), southern Brazil, another individual was observed in 2018 and the specimen has been deposited in the scientific collection of the Universidade Federal da Bahia. This suggests that a larger volume of information about the occurrence of $A$. manicatum in Brazil is still restricted to scientific institutions.

Therefore, to better understand the current occurrence and distribution range of $A$. manicatum in Brazil, new field works are welcome if focused on sampling this exotic bee species. Even those localities where only one individual was collected may represent a research bias. We also suggest that Brazilian scientific institutions should receive stimulus and more financial support to make the data inside their collections digitally available to a broad audience. This may promote large-scale monitoring of both native and exotic Anthidium bees.

According to our phenology analysis, A. manicatum seems to be active throughout the year, although it shows a clear tendency of presenting two generations (bivoltine), one in May and one in November. It is known that $A$. manicatum may modify its voltinism depending on the region its population inhabits. For example, it may be univoltine in a non-native place such as Utah, USA, in which generations are active from July to October (StRANGe et al. 2011), as well as in native regions, such as Germany, where it is active in August (WIRTZ et al. 1992). On the other hand, it may be bivoltine in Italy with one generation in May, as in Brazil, and one in October (Mueller \& Wolf-Mueller 1993). Knowing that $A$. manicatum most likely has two clear generations in Brazil (May, November) may help researchers increase their chances of observation and collection in future field works.

The wide occurrence of $A$. manicatum in several places of the world has been attributed to its nesting behavior and its large bioclimatic amplitude (STRANGE et al. 2011). It appears to negatively affect the acquisition of floral resources and may cause the transmission of parasites and pathogens to other bee species (Russo 2016). With occurrence data and their corresponding bioclimatic values, it was possible to infer how and to which extent $A$. manicatum occupies the bioclimatic niche region of native Anthidium bees such as $A$. sertanicola and, more widely, A. latum. This indicates that $A$. latum most likely suffers a stronger ecological pressure than $A$. sertanicola by $A$. manicatum. Therefore, we suggest that field works could corroborate this finding and its implications to Anthidium bees.
The successful settlement and subsequent dispersal of exotic species may be attributed to features such as: (1) extended longevity of adults; (2) broad diet, i.e., few restrictions to specific host plants; (3) eusociality, which does not involve the studied bee species; (4) passive dispersal by human activities that accelerate the displacement; (5) voltinism, i.e., multiple generations per year; and (6) large body size that appears to facilitate faster active dispersal (FAHRNER \& AuKema 2018). Therefore, to a possible survey of $A$. manicatum in Brazil, most of the above characteristics should be considered, including large-scale samplings for at least two years to catch the seasonal pattern of this species.

The capacity for long and fast dispersal is vital for the survival of exotic species (FAHRner \& Aukema 2018). Our data show that, during almost 90 years of records in Brazil, $A$. manicatum was detected in, at least, nine states, suggesting a dispersal velocity of about $46 \mathrm{~km}$ per year. This expansion rate is practically seven times lower than that of $A$. mellifera scutellata, which, within 15 years, had already been detected in all Brazilian states in a geographic expansion of $321 \mathrm{~km}$ per year (MiCHENER 1973). However, it is worth saying that the social behavior of honey bees may allow them to disperse faster due to features such as: (a) populous nests with labor and task division; (b) a mother queen that may follow its swarms for long distances to fund new colonies; and (c) advanced geolocation, communication and recruitment mechanisms that facilitate the search for novel places to forage and nest.

Our study demonstrates the importance of scientific collections since their digitalized data allowed us to historically track the occurrence of an exotic solitary bee species in Brazil. Despite the small number of sampled individuals over the decades, A. manicatum has been recorded from their first notification almost 90 years ago to the present. As we observed, most specimens were males (1.7x). Nevertheless, this may be an underreporting because most removed data were of specimens without information on sex. Similarly, the larger sampling of $A$. manicatum in Brazil's south and southeast regions seems to indicate that these places harbor a larger number and/or older scientific collections, causing a bias in our data.

In summary, our data suggest that the best periods to sample A. manicatum in Brazil are May (late autumn) and November (late spring) when these generations seem to be more active. Our study also supports that $A$. manicatum may occupy a fraction of bioclimatic niche region of, at least, two of five native Anthidium bees. Thus, while with $A$. sertanicola, whose distribution range appears to be further south in Brazil, the overlap is low (<5\%), with $A$. latum, whose distribution range is larger, the probability of overlap reached about $15 \%$. Therefore, we strongly suggest that a field monitoring of $A$. manicatum in Brazil should occur together with the survey of native Anthidium species, especially where co-occurrence is common. Finally, we recommend the maintenance of both the training of young people and the financial support to scientific institutions since the efficiency and quality of digitalized data allow a remote assessment of biodiversity that needs to be continuously monitored.

\section{ACKNOWLEDGMENTS}

The authors are grateful to Favízia Freitas de Oliveira for consulting databases of possible Anthidium manicatum specimens not yet inserted in platforms such as speciesLink e Global Biodiversity Information Facility (GBIF). CFS would like to thank the Coordination for the Improvement of Higher Education Personnel (CAPES) of the Ministry of Education (MEC) for funding the postdoctoral fellowship of the National Postdoctoral Program (PNPD, Finance Code $88882.314829 / 2019-01)$. CAB is grateful to the Programa 
de Bolsas Pesquisa-Aluno (BPA/ PUCRS). BB would like to thank the National Council for Scientific and Technological Development (CNPq) for the research productivity grant to the second author (Finance Code 311184/2016-2).

\section{REFERENCES}

Acosta, AL, TC Giannini, VL Imperatriz-Fonseca \& AM Saraiva, 2016. Worldwide alien invasion: a methodological approach to forecast the potential spread of a highly invasive pollinator. PLOS ONE, 11: 1-25. DOI: https://doi.org/10.1371/journal.pone.0148295

Agostinelli, C \& U Lund, 2017. R package "circular": circular statistics (version 0.4-93). Available on: <https://cran.rproject.org/web/packages/circular/index.html>.

Aizen, MA, C Smith-Ramírez, CL Morales, L Vieli, A Sáez, RM Barahona-Segovia, MP Arbetman, J Montalva, LA Garibaldi, DW Inouye \& LD Harder, 2019. Coordinated species importation policies are needed to reduce serious invasions globally: The case of alien bumblebees in South America. Journal of Applied Ecology, 56: 100-106. DOI: https://doi.org/10.1111/1365-2664.13121

Bivand, RS, E Pebesma \& V Gómez-Rubio, 2013. Applied spatial data analysis with R. Springer, New York.

Chamberlain, S, V Barve, D Mcglinn \& D Oldoni, 2020. rgbif: Interface to the Global Biodiversity Information Facility API. Available on: <https://cran.r-project.org/web/packages/ rgbif/index.html>.

Fahrner, S \& BH Aukema, 2018. Correlates of spread rates for introduced insects. Global Ecology and Biogeography, 27: 734-743. DOI: https://doi.org/10.1111/geb.12737

Gonzalez, VH \& TL Griswold, 2013. Wool carder bees of the genus Anthidium in the Western Hemisphere (Hymenoptera: Megachilidae): diversity, host plant associations, phylogeny, and biogeography. Zoological Journal of the Linnean Society, 168: 221-425. DOI: https://doi.org/10.1111/zoj.12017

Grimaldi, D \& MS Engel, 2005. Evolution of the insects. Cambridge University Press. Cambridge University Press, New York.

Hijmans, R, 2017. raster: Geographic Data Analysis and Modeling. Available on: <https://cran.r-project.org/web/ packages/raster/index.html>.

Ihaka, R \& R Gentleman, 1996. R: a language for data analysis and graphics. Journal of Computational and Graphical Statistics, 5: 299-314.

IPBES, 2016. IPBES - Intergovernmental Science-Policy Platform on Biodiversity and Ecosystem Services. Summary for policymakers of the assessment report of the intergovernmental science-policy platform on biodiversity and ecosystem services on pollinators, pollination. Secretariat of the intergovernmental sciencepolicy platform on biodiversity and ecosystem services, Bonn.

Klein, A-M, BE Vaissière, JH Cane, I Steffan-Dewenter, SA Cunningham, C Kremen \& T Tscharntke, 2007. Importance of pollinators in changing landscapes for world crops. Proceedings of the Royal Society B: Biological Sciences, 274: 303-313. DOI: https://doi.org/10.1098/rspb.2006.3721

Lysy, M, AD Stasko \& HK Swanson, 2014. nicheROVER: (Niche) (R)egion and Niche (Over)lap metrics for multidimensional ecological niches. Available on: <https://cran.r-project. org/web/packages/nicheROVER/>.

Michener, CD, 1973. The Brazilian honeybee. Bioscience, 23: 523-527. DOI: https://doi.org/10.2307/1296479

Morales, CL, MP Arbetman, SA Cameron \& MA Aizen, 2013. Rapid ecological replacement of a native bumble bee by invasive species. Frontiers in Ecology and the Environment, 11: 529-534. DOI: https://doi.org/10.1890/120321

Mueller, UG \& B Wolf-Mueller, 1993. A method for estimating the age of bees: age-dependent wing wear and coloration in the wool-carder bee Anthidium manicatum (Hymenoptera: Megachilidae). Journal of Insect Behavior, 6: 529-537. DOI: https://doi.org/10.1007/bf01049530

Naimi, B, NAS Hamm, TA Groen, AK Skidmore \& AG Toxopeus, 2014. Where is positional uncertainty a problem for species distribution modelling? Ecography, 37: 191-203. DOI: https://doi.org/10.1111/j.1600-0587.2013.00205.x

Ollerton, J, R Winfree \& S Tarrant, 2011. How many flowering plants are pollinated by animals? Oikos, 120: 321-326. DOI: https://doi.org/10.1111/j.1600-0706.2010.18644.x

Potts, SG, JC Biesmeijer, C Kremen, P Neumann, O Schweiger \& WE Kunin, 2010. Global pollinator declines: trends, impacts and drivers. Trends in Ecology \& Evolution, 25: 345-353. DOI: https://doi.org/10.1016/j.tree.2010.01.007

R Core Team, 2018. R: A language and environment for statistical computing. The R Foundation for Statistical Computing, Vienna, Austria. Available on: <https://cran.rproject.org/>

Russo, L, 2016. Positive and negative impacts of non-native bee species around the world. Insects, 7: 1-22. DOI: https://doi.org/10.3390/insects7040069

Sakai, A.K., FW Allendorf, JS Holt, DM Lodge, J Molofsky, KA With, S Baughman, RJ Cabin, JE Cohen, NC Ellstrand, DE McCauley, P O'Neil, IM Parker, JN Thompson \& SG Weller, 2001. The population biology of invasive species. Annual Review of Ecology, Evolution, and Systematics, 32: 305-332. DOI: https://doi.org/10.1146/annurev. ecolsys.32.081501.114037

Silveira, FA, GAR Melo \& EAB Almeida, 2002. Abelhas brasileiras: sistemática e identificação. Fundação Araucária, Belo Horizonte.

Strange, JP, JB Koch, VH Gonzalez \& L Nemelka, 2011. Global invasion by Anthidium manicatum (Linnaeus) (Hymenoptera: Megachilidae): assessing potential distribution in North America and beyond. Biological Invasions, 13: 2115-2133. DOI: https://doi.org/10.1007/ s10530-011-0030-y

Swanson, HK, M Lysy, M Power, AD Stasko, JD Johnson \& JD Reist, 2015. A new probabilistic method for quantifyingdimensional ecological niches and niche overlap. Ecology, 96: 318-324.

Urban, D, 2002. O gênero Anthidium Fabricius na América do Sul: chave para as espécies, notas descritivas e de distribuição geográfica. Revista Brasileira de Entomologia, 46: 495-513. DOI: https://doi.org/10.1590/s008556262002000400003

Vollet-Neto, A, B Blochtein, BF Viana, CF Santos, C Menezes, $P$ Nunes-Silva, $R$ Jaffé \& $S$ Amoedo, 2018. Desafios e recomendações para o manejo e transporte de polinizadores. Associação Brasileira de Estudos das Abelhas, São Paulo.

Wirtz, P, S Kopka \& G Schmoll, 1992. Phenology of two territorial solitary bees, Anthidium manicaturn and A. florentinum (Hymenoptera: Megachilidae). Journal of Zoology, 228: 641-651. DOI: https://doi.org/10.1111/j.1469-7998.1992. tb04461.x

********** 


\section{Suggestion citation:}

dos Santos, CF, CA de Barros, R Halinski \& B Blochtein, 2020. Occurrence and ecological data on an exotic solitary bee accidentally introduced in Brazil. EntomoBrasilis, 13: e891.

Available in: doi: 10.12741/ebrasilis.v13.e891
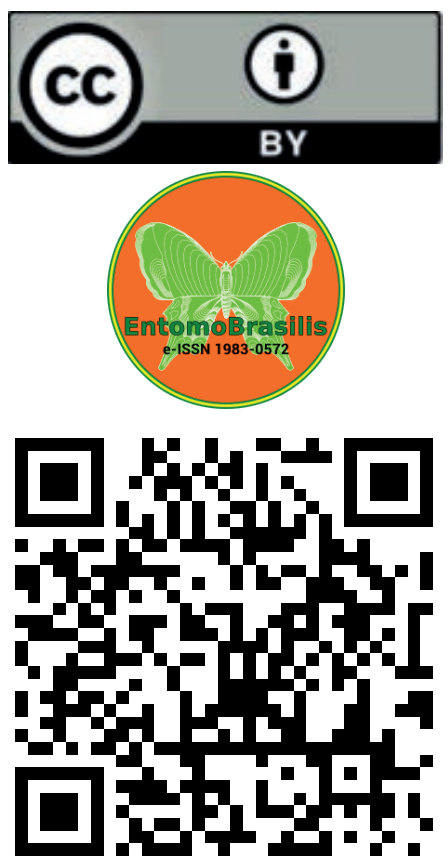